\title{
The Relationship Between Blood Alcohol Concentration and Injury Severity in Patients Admitted to The Hospital Emergency Department After a Motor Vehicle Accident
}

\author{
Serkan Doğan', Nurdan Acar², Arif Alper Çevik², Engin Özakın², Filiz Baloğlu Kaya², Didem Arslantaş \\ 'Department of Emergency Medicine, Kanuni Sultan Süleyman Training and Research Hospital, İstanbul, Turkey \\ 2Department of Emergency Medicine, Eskişehir Osmangazi University School of Medicine, Eskisehir, Turkey \\ ${ }^{3}$ Department of Public Health, Eskişehir Osmangazi University School of Medicine, Eskişehir, Turkey
}

\begin{abstract}
Aim: The aim of our study is to establish the point at which a high blood alcohol concentration (BAC) in patients admitted to a hospital's emergency department (ED) after an automobile accident can increase the severity of the injury and influence the survival and death rates.

Materials and Methods: Our study is a prospective performed on patients $\geq 18$ years of age admitted to the ED for in-car road accidents (ICRA) between September 15, 2011 and September 14, 201214-09-2012. Information such as demographic features, trauma score systems, BACs, hospital charges, discharge, hospitalization, and death of the patients was recorded.

Results: The BACs of 52 out of a total of 324 patients were determined to be above normal limits ( $50 \mathrm{mg} / \mathrm{dL})$. The clinical condition of patients with a BAC above normal limits was relatively worse $(42.9 \%)$ than those with a BAC within normal limits $(p<0.05)$. The BAC was above normal limits for $30.0 \%$ of the hospitalized patients, for $50 \%$ of surgical patients, and for $45.5 \%$ of deceased patients.

Conclusion: This study determined that there is a relationship between a high BAC and injury severity for patients admitted to the ED for ICRA and that a high BAC negatively affects the survival rate and increases the death rate in emergency medicine.
\end{abstract}

Keywords: Blood alcohol concentration, in-car road accident, injury severity, emergency unit

\section{Introduction}

Trauma, especially during automobile accidents, is the primary cause of death among young people aged 1-44 years in developed countries (1). According to estimates by the World Health Organization (WHO), while road accidents were placed ninth for the cause of death in 2004, they will become the fifth in 2030: 2.4 million people are expected to die in automobile-related accidents (2). A significant increase has been observed in trauma associated with the consumption of alcohol, with road accidents at the top of the list. These represent $23 \%$ of admissions to a hospital's emergency department (ED) $(3,4)$. In many countries, the consumption of alcohol by drivers is limited by law. In Turkey, the legal limit is defined as 0.50 promille (50 mg/dL) (5).

Easy access to alcohol creates individual, social, economic, and health problems. Alcoholic people can be the source of problems not only for their family and friends but also for society at large. In the management of patients admitted for automobile accidents, alcohol, injury severity, and the resultant damage it may cause (including handicap and death) are an important part of social health policies because of high economic costs.

Physiological, anatomical, and combined trauma scoring systems (TSSs) are used to determine injury severity and to estimate death and handicap rates (6).

In our study, our primary objective is to determine whether the blood alcohol concentration (BAC) in patients admitted to the hospital for in-car road accidents (ICRA) can alert emergency physicians about potential injury severity and survival and death outcomes in order to direct appropriate patient management and undertake carefully planned action in the diagnosis and treatment of these patients. Our secondary objective is to observe whether hospital charges increase for patients with BACs above normal limits.

Correspondence to: Serkan Doğan e-mail: sercem2003@hotmail.com 


\section{Materials and Methods}

\section{Study design}

This prospective study is an observational and descriptive research performed in the Emergency Medicine Department of the Faculty of Medicine of Eskişehir Osmangazi University (ESOGÜ) between September 2011 and September 2012. Approval was obtained for this study from the Ethics Committee of this university on October 31, 2011 under Reference 266. We informed our patients regarding this study. Patients $\geq 18$ years of age who were admitted to the ED of this university between September 15, 2011 and September 14, 2012 (over 1 year) for ICRA were included in the study.

\section{Results, measurements, and data collection}

Trauma management of all ICRA patients was performed according to the actual advanced trauma life-support guidelines. The vital statistics of the patients who were evaluated by the trauma team were recorded, and primary care and necessary medical interventions were applied simultaneously. Data collection forms were used to collect the following: demographic data of the patients; details of each accident and patient; results of the TSSs, which included the Glasgow coma scale (GCS), abbreviated injury scale (AIS), revised trauma score (RTS), injury severity score (ISS), trauma and injury severity score (TRISS), as well as BACs; interventions made and analyses requested; all consultations; and data on discharge, hospitalization, and death. Hospital charges were also recorded as part of the data.

\section{Laboratory alcohol analysis}

An additional tube of blood from the first blood samples was sent to the laboratory for the determination of BAC, which was analyzed using an Olympus AU400 autoanalyzer, Indigo desktop device, and Thermo Fisher Scientific Ethyl Alcohol Assay A-E kit. When considering $B A C$ and its effects on the organism, the blood alcohol levels were separated into four groups: legal limit (0-50 mg/dL), slightly inebriated (51-150 mg/dL), moderately inebriated (151-200 mg/dL), and severely inebriated ( $\geq 201 \mathrm{mg} / \mathrm{dL})(7)$.

\section{Criteria for study inclusion and exclusion}

Patients aged $\geq 18$ years involved in an ICRA were included in this study. Patients $<18$ years, accidents other than ICRA, patients transferred from any other center where the first intervention was already made, patients with an AIS score of 6 (patients who are not treated and patients dead on arrival (DOA) to the ED), and patients who did not give their approval were not included in this study.

\section{Statistical analysis}

After calculations, the trauma scores were recorded. GCS was scored by evaluating three main functions, namely, eye opening, oral, and motor responses. The best prognosis obtained was 15 points, while the worst was 3 points. RTS, GCS, respiratory rates, and systolic blood pressure values were calculated by scoring. The scores defined were multiplied by the coefficients and then summed (RTS = $0.9368 \times$ GCS $+0.7326 \times$ SKB score $+0.2908 \times$ SS score). In our study, this calculation was made using the RTS calculator provided on the www.trauma.org Web site. The injuries were scored from 0 to 5, using AIS 90-94 scales according to the anatomical regions. The squares of the scores obtained for the three anatomical regions with the highest scores were summed. The scores of the other regions were not included in the calculation. A score of 75 was considered to be the highest score. Our study used the ISS calculator on the www.trauma.org Web site for the ISS score calculation. TRISS was calculated by adding the age index to RTS and ISS. The upper limit for the age index was 55 years. Due to calculation difficulties, we used the TRISS calculator provided on the www.trauma.org Web site (8). Data analyses were performed using the Statistical Package of Social Sciences 20 (IBM SPSS Statistics; Armonk, NY, USA) software. The chi-square, Student's T-test, Mann-Whitney $\mathrm{U}$ test, Kruskal-Wallis $\mathrm{H}$ test, and Pearson and Spearman correlation tests were used. The value of $p<0.05$ was considered statistically significant, with a $95 \%$ confidence interval.

\section{Results}

The total number of admissions in 1 year was 324: 210 (64.8\%) patients were men and 114 (35.2\%) were women; the BAC was above normal limits for 52 (16\%) patients. Alcohol consumption was the highest in the 35- to 44-year-old age group, i.e., $26 \%(p<0.05)$. The alcohol consumption rate in men (21.9\%) was higher than that in women $(5.3 \%)$ $(p<0.05)$. It was observed that $169(52.2 \%)$ patients admitted after an ICRA were drivers. For 34 (20.1\%) patients, the BAC was above normal limits $(p<0.05)$. We detected that $240(74.1 \%)$ patients admitted after an ICRA had an unfastened seatbelt and the BAC for $41(17.1 \%)$ patients was above normal limits. We observed that 41 (78.8\%) of 52 patients for whom BAC was above normal limits had an unfastened seatbelt. It was established that 243 (75\%) and 81 (25\%) of the accidents occurred in normal and abnormal (rainy, snowy, foggy, and icy) weather/road conditions, respectively. In 18 (22.2\%) of the accidents occurring in abnormal weather/road conditions, the BAC was above normal limits. For patients with a BAC above normal limits, the general clinical condition was $42.9 \%$ worse $(p<0.05)$ than that for those within normal BAC limits. The most frequent cases of ICRA with a BAC above normal limits occurred during spring (21.7\%); in March, it was $31.2 \%$.

The most frequent arrival times of ICRA patients with a BAC above normal limits to the ED were between 00:00 and 07:59 AM (32.2\%). The distribution of the arrivals over 24 hours is shown in Figure $1(p<0.05)$.

When considering the medical interventions provided to patients with a BAC within normal limits, the intubation rate was $8 \%$ and the reanimation rate was $4 \%$, whereas these were $38.5 \%$ and $46.2 \%$, respectively, for patients with a BAC above normal limits $(p<0.05)$. A statistically positive relationship was established between a BAC above normal limits and injury severity. The relationship between a BAC above normal limits and TSS is enumerated in Table $1(p<0.05)$.

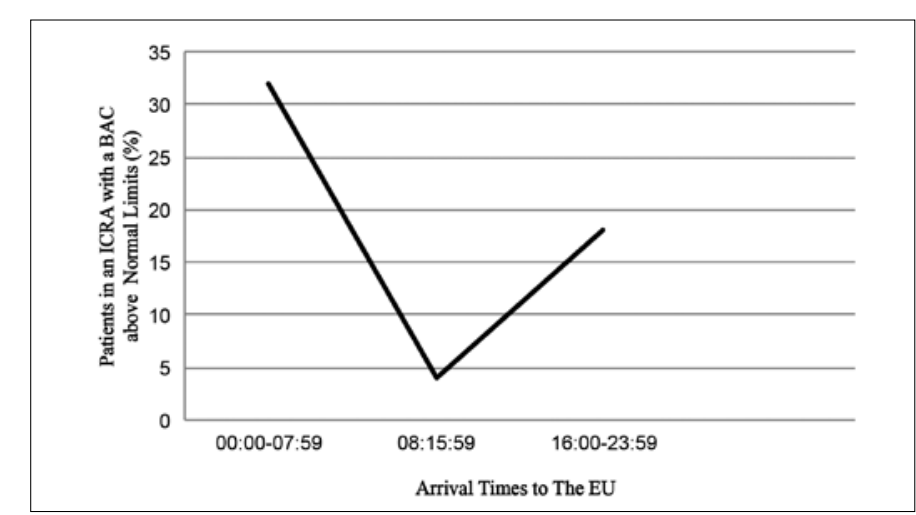

Figure 1. Relationship between ICRA patients with a BAC above normal limits and their arrival times to the ED 
In addition to the statistically positive relationship between a BAC above normal limits and the injury severity in patients, this study determined that there is a statistically significant increase in injury severity associated with the increase of BAC. Table 2 shows the relationship between BAC, divided into four groups, and TSS $(p<0.05)$.

While the median value of the number of consultations requested in the ED management process for patients with a BAC above normal limits is $1(0-5)$, this value was $0(0-7)$ for patients with a normal or subnormal BAC $(p<0.05)$. When considering the time spent by patients in ED (in hours), it was determined that patients with a BAC above normal limits spent, at the most, 12 hours, whereas patients with a normal or subnormal BAC spent at the most 24 hours $(p<0.05)$.

When considering the clinical output of patients, this study established that $30 \%$ of the patients hospitalized in services, $45.5 \%$ of the

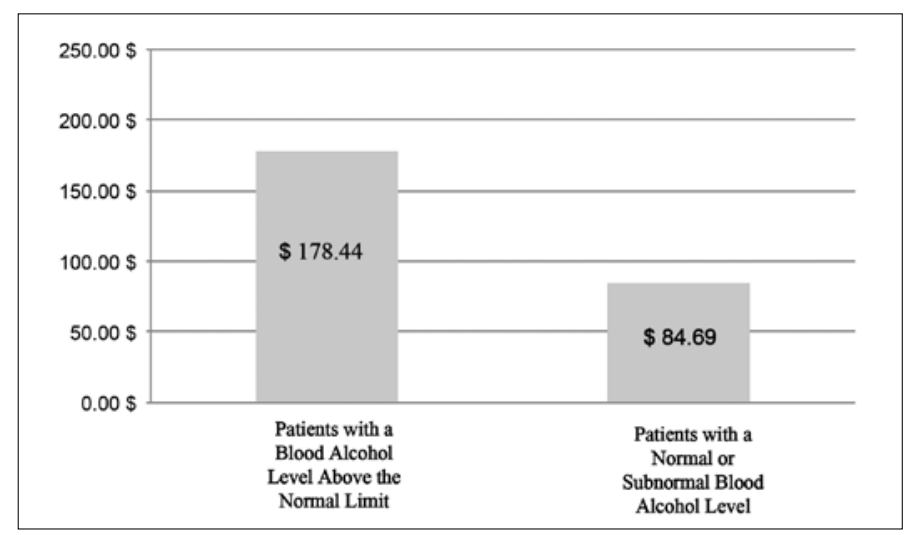

Figure 2. Relationship between a BAC above normal limits and the hospital charges

Table 1. Relationship between a BAC above normal limits and TSS

\begin{tabular}{|l|c|c|c|}
\hline $\begin{array}{l}\text { Trauma scoring } \\
\text { system }\end{array}$ & $\begin{array}{c}\text { Alcohol detected } \\
\mathbf{X} \pm \text { SE }\end{array}$ & $\begin{array}{c}\text { No alcohol } \\
\mathbf{X} \pm \text { SE }\end{array}$ & $\begin{array}{c}\text { Statistical } \\
\text { value }\end{array}$ \\
\hline GCS & $12.84 \pm 0.61$ & $14.50 \pm 0.12$ & $\mathrm{t}=2.63 \mathrm{p}<0.05$ \\
\hline RTS & $6.97 \pm 0.29$ & $7.67 \pm 0.50$ & $\mathrm{t}=2.36 \mathrm{p}<0.05$ \\
\hline TRISS & $\begin{array}{c}\text { Alcohol detected } \\
\text { Median } \\
\text { (min-max) }\end{array}$ & $\begin{array}{c}\text { No Alcohol } \\
\text { Median } \\
\text { (min-max) }\end{array}$ & \\
\hline ISS* & $6(0-66)$ & $3(0-57)$ & $\mathrm{z}=9.53 \mathrm{p}<0.05$ \\
\hline
\end{tabular}

*The ISS parameter was analyzed using the Mann-Whitney $\mathrm{U}$ test. patients who died, and $50 \%$ of the patients who required surgery had a BAC above normal limits $(p<0.05)$. The hospital charges calculated for the time spent at the hospital was higher for patients with a BAC above normal limits than for those within normal limits. The median value of hospital charges for patients with a BAC above normal limits was \$178.44 (\$14.94-14143), while it was \$84.69 (\$12.34-28642) for patients with a normal or subnormal BAC. The relationship between a BAC above normal limits and the hospital charges is given in Figure $2(p<0.05)$.

\section{Discussion}

The patients admitted to the ED for ICRA were evaluated for death and handicap by the admissions department at the multidisciplinary trauma center and finalized as soon as possible. In our study, increases were observed in the injury severity, death, handicap, and hospital charges for patients with a BAC above normal limits. The risks increase with the increase in the BAC. Thus, in our study, the aim was to determine how to perform medical diagnosis and treatment in a more careful and planned manner by taking into consideration the increased risks in the ED.

Most road accidents involving patients with a BAC above normal limits were observed in the 35-44-year-old age group, which is considered to be the most frequent age group for ICRA patients. In literature, Mason et al. (9) reported that the most frequent ICRA patients with a BAC above normal limits fall within the 21-24-year-old age group, while Kesen et al. (10) cited the same to be the 35-44-yearold age group. Evidently, people involved in road accidents with a BAC above normal limits constitute the young and productive population. Alcohol is considered to be one of the most significant factors contributing to the loss of life and property, loss of labor force, and lifelong disability of people all over the world.

We determined that the most frequent arrival times to the ED for ICRA patients with a BAC above normal limits occurred between 00:00 and 07:59 AM (32.2\%). In the study by Kesen et al. (10), the patients were mostly taken to the hospital between 00.00 and 05:59 AM (60.5\%). This can be explained by the consumption of alcohol during the evening and driving under the influence of alcohol, which leads to road accidents and the transfer of patients to the hospital after midnight.

The utilization of a seatbelt is one of the most efficient ways to reduce deaths in road accidents (11). In Turkey, the rate for utilization of seatbelt is between $4.7 \%$ and $37.5 \%$ (12). In literature, according to the study by Hitosugi et al. (13), studies about injury severity in the case of ICRAs revealed that the seatbelt utilization rate was $20 \%$. The study by Newman et al. (14) revealed that $71 \%$ of the patients did

Table 2. Relationship between the BAC groups and TSS

\begin{tabular}{|c|c|c|c|c|c|}
\hline $\begin{array}{l}\text { Trauma scoring } \\
\text { systems }\end{array}$ & $\begin{array}{c}\text { Legal }(0-50 \mathrm{mg} / \mathrm{dL}) \\
\mathrm{X} \pm \mathrm{SE}\end{array}$ & $\begin{array}{c}\text { Slight (51-150 mg/dL) } \\
X \pm S E\end{array}$ & $\begin{array}{c}\text { Medium }(151-200 \mathrm{mg} / \mathrm{dL}) \\
X \pm S E\end{array}$ & $\begin{array}{c}\text { Severe (201 mg/dL and over) } \\
X \pm S E\end{array}$ & $\begin{array}{l}\text { Statistical } \\
\text { value }\end{array}$ \\
\hline $\mathrm{GCS}^{1}$ & $14.51 \pm 0.12$ & $13.30 \pm 1.10$ & $12.50 \pm 1.18$ & $11.66 \pm 1.40$ & $F=8.98 p<0.05$ \\
\hline \multirow[t]{2}{*}{ TRISS ${ }^{1}$} & $96.42 \pm 0.82$ & $94.01 \pm 5.38$ & $86.41 \pm 7.01$ & $77.08 \pm 9.75$ & $F=7.85 p<0.05$ \\
\hline & Median (min-max) & Median (min-max) & Median (min-max) & Median (min-max) & \\
\hline
\end{tabular}


not have their seatbelts fastened; in our study, this value is $74.1 \%$, which is in agreement with earlier literature. The BAC was above normal limits for $17.1 \%$ of the patients who did not fasten their seatbelt. In addition, we also observed that 41 (78.8\%) out of 52 patients, for whom the BAC was above normal limits, had an unfastened seatbelt. We suggest that the increased self-confidence of drivers under the influence of alcohol and the reduction of reality testing by relevant authorities leads to the situation of unfastened seatbelts. Therefore, both public education and legal sanctions for the generalized use of seatbelts will engender positive results.

TSSs are very important for the efficient evaluation of trauma patients and determination of treatment protocols, prognosis of death and disability, and creation of national health policies for associated trauma (15). In our study of patients with a BAC above normal limits, while the GCS, RTS, and TRISS decreased, the ISS increased. The study by Kesen et al. (10) reported that the GCS was under 10 for $22.7 \%$ of ICRA drivers with a BAC above normal limits. For drivers with a normal or subnormal BAC, the GCS score did not reduce below 10 . In our study, while the GCS was $14.50 \pm 0.12$ for patients with a normal or subnormal BAC, the GCS decreased to $12.84 \pm 0.61$ for patients with a $B A C$ above normal limits. According to these data, it is possible to say that a BAC above normal limits increases injury severity.

When considering the medical interventions provided to patients admitted to the ED after an ICRA and after physical examination and taking the patient's history, it was observed that death and injury were proportional. As per the literature, the study by Bilgin et al. (16) revealed that intubation resulted in the reanimation of $4.7 \%$ patients involved in an automobile accident. In our study, the intubation and reanimation rates were $8 \%$ and $4 \%$, respectively, for patients with a normal or subnormal BAC: this result conforms to the literature. In contrast, these rates were $38.5 \%$ and $46.2 \%$, respectively, for patients with a BAC above normal limits. The differences in these rates indicate that the increase of injury severity for ICRA patients with a BAC above normal limits is significant.

In our study, when considering the consultation request rates of patients after their evaluation in ED, the median value for patients' consultation with a normal or subnormal BAC was found to be 0 (0-7). In literature, the study by Kocak et al. (17) determined that between 1 and 5 consultations were requested for 50 out of 57 patients and that this consultation number increased further in patients who had multiple traumas (43.8\%). Our study determined that the median value for consultation requested for patients with a BAC above normal limits increased by 1 (0-5). For patients with a BAC above normal limits, the increase of consultation requests is another indicator of the severity of injuries and more regions affected by trauma. Of the patients who died, $45.5 \%$ had a BAC above normal limits, and $50 \%$ of the surgery patients had a BAC above normal. The study by Fabbri et al. (18) reported that in $33-69 \%$ of the dead and $8-29 \%$ of outcomes other than death, the BAC was above normal limits. The study by Akay et al. (19) found that all the patients who died had a BAC above normal limits. This situation is a clear indicator of the increase in injury severity in road accidents involving a BAC above normal limits. Furthermore, only $14.9 \%$ of the patients with a BAC above normal limits were discharged, whereas $85.1 \%$ of the patients with a normal or subnormal BAC were discharged. This shows that injury severity is higher in ICRA with a BAC above normal limits, and the hospitalization rate and hospital charges are significantly higher. Moreover, when considering the hospitalization time of the patients admitted to the ED after an ICRA, it was determined that patients with a BAC above normal limits spent at the most 12 hours, while patients with normal or subnormal BAC spent at the most 24 hours. As the injury severity of the patients having an ICRA with a BAC above normal limits is high, they are immediately operated and/or hospitalized and leave the ED rapidly. For the patients with a normal or subnormal $B A C$, as the injury severity is low, the requirement of operation and/ or hospitalization is reduced and they are under trauma monitoring in the ED. A shorter time spent in the ED is an indicator that the injury severity of patients with a BAC above normal limits is higher than in patients with normal or subnormal BAC.

When considering the hospital charges incurred, the average charge for patients with a BAC above normal limits was $\$ 178.44$, as opposed to $\$ 84.68$ for patients with a normal or subnormal BAC. In the study by Akay et al. (19), the average hospital charge for patients with a BAC above normal limits was $\$ 175.49$, while it was $\$ 67.63$ for patients with a normal or subnormal BAC. In another study by Akgul et al. (20), an average hospital charge of $\$ 343.65$ per patient was reported. The reason this hospital charge exceeded to double that of other patients with a BAC above normal limits is that as the injury severity increases, there is a corresponding increase in charges incurred due to intervention, imaging, procedures, requested consultations, and hospitalization time. The financial losses that occur as a result of a road accident are higher even more for patients with a BAC above normal limits. We predict that the costs will increase further when the loss of labor force, loss of function, and lifelong treatment costs are factored.

There are many factors that increase the severity of injury in all trauma patients, particularly in the case of traffic accidents. Other important factors that increase the severity of injury and chance of death include the following: older age (21); injured at site (head trauma); multiple trauma (22); presence of additional diseases (23); additional time required to arrive at the ED and time spent in the ED; and failure to comply with traffic rules such as seatbelt use, wearing helmets, using vehicles at excessive speeds, and driving under the influence of alcohols or drugs. On the basis of the fact that all of these factors increase the severity of injury in traffic accidents, we emphasized that increased BAC could negatively affect the severity of injury and death rates in our study.

\section{Study limitations}

The AIS 6 patients, i.e., those who are included in the fatal group and who were not actually treated, were not admitted to the ED of the university, but were directly transferred to the morgue; they are, therefore, not included in this study. As these patients were not treated in the ED and as their BACs were not analyzed, the lack of their statistics can be considered as a limitation of this study.

As the study was performed at the $3^{\text {rd }}$ ED level, the non-inclusion of patients admitted to the $1^{\text {st }}$ and $2^{\text {nd }}$ ED levels of the hospitals in the city and/or the country; the absence of detailed information about the demographic features, general situation, trauma scoring, BACs, clinical outcomes, and hospital charges of these patients; and the possibility of these differences influencing the results can be considered as a limitation of this study.

\section{Conclusion}

Because the trauma scores are higher for injury severity and survival and death rates are significantly affected for patients with 
a high BAC, we consider-as emergency physicians-the BAC to be a useful tool for patient management in emergency medicine, which can help in the preparation of a more careful plan of action in treatment directed toward more successful clinical outcomes. Moreover, we believe that the knowledge of high BACs in ICRAs will be beneficial toward understanding the increases in hospital charges in order to make plans to prevent such increases in the future.

Ethics Committee Approval: Ethics committee approval was received for this study from the ethics committee of Eskişehir Osmangazi University School of Medicine.

Informed Consent: Written informed consent was obtained from patients who participated in this study.

Peer-review: Externally peer-reviewed.

Conflict of Interest: No conflict of interest was declared by the authors.

Financial Disclosure: The authors declared that this study has received no financial support.

\section{References}

1. ATLS Subcommittee; American College of Surgeons' Committee on Trauma; International ATLS working group. Advanced trauma life support (ATLS ${ }^{\circledast}$ ): the ninth edition. J Trauma Acute Care Surg 2013; 74: 1363-6.

2. Global Status Report on Road Safety: time for action. Geneva, World Health Organization (WHO), 2009. Available from: URL: http:/www.who. int/violence_injury_preventıon/road_safety_status/2009.

3. Yoonhee $C$, Jung $K$, Eo E, Lee $D$, Kim J, Shin $D$, et al. The relationship between alcohol consumption and injury in ED trauma patients. Am J Emerg Med 2009; 27: 956-60. [CrossRef]

4. Fabbri A, Marchesini G, Morselli-Labate AM, Rossi F, Cicognani A, Dente $M$, et al. Positive blood alcohol concentration and road accidents. A prospective study in an Italian emergency department. Emerg Med J 2002; 19: 210-4. [CrossRef]

5. Sayal A, Aydin A, Demirkan K, Isimer A. Alcohol use and rate of crime. Gulhane Med J 2005; 47: 14-7.

6. Aydin SA, Bulut M, Ozgüç H, Ercan I, Türkmen N, Eren B, et al. Should the New Injury Severity Score replace the Injury Severity Score in the Trauma and Injury Severity Score? Ulus Travma Acil Cerrahi Derg 2008; 14: 308-12.

7. Baban N, Kurt K, Kaptanoglu K, Kaptanoglu SA, Baban A, Acar U, et al. Forensic Toxicology, Istanbul. Institute of Forensic Medicine Publications-8 2003: 136-52.
8. Scoring systems. Trauma.org care of the injured site. Available from: URL:http:/www.trauma.org/index.php/main/article/calculate.

9. Mason J, Fitzpatrick K, Seneca D, Davinroy T. Identification of in appropriate driving behaviors. J Transp Eng 1992; 118: 281-98. [CrossRef]

10. Kesen J, Topbas M, Gunduz K, Yandi M. The level of the drinking drivers who reason of traffic accident apply to the emergency department of the KTU Farabi Hospital. Turk J Emerg Med 2004; 2: 51-4.

11. Bektas S, Hinis MA. A Predictor Model for Effective Parameters of Seat Belt Usage Among Automobile Drivers. Erciyes University, Institute of Science Magazine 2009; 25: 208-22.

12. Demircan A, Aygencel SG, Karamercan M, Bildik F, Keles A. The prevalence of seatbelt usage among university lecturers. Ulus Travma Acil Cerrahi Derg 2009; 15: 176-9.

13. Hitosugi M, Takatsu A. Injury severity in motor vehicle occupants. Legal Med 2000; 2: 166-70. [CrossRef]

14. Newman RJ, Jones IS. A prospective study of 413 consecutive car occupants with chest injuries. J Trauma Acute Care Surg 1984; 24: 129-35. [CrossRef]

15. Ozguc H. Trauma Scoring Systems. In: Sahinoglu AH. editor. Intensive care issues and treatment principles. 2nd edition. Ankara: Turkey Clinics 2003.p.430-3.

16. Bilgin UE, Meral O, Kocak A, Aktas EÖ, Kıyan S, Altuncı YA. Legal examination of the patients admitted to the Emergency Service of Ege University Hospital due to traffic accidents in 2011. Ege Journal of Medicine 2013; 52: 93-9.

17. Kocak S, Ucar K, Bayır A, Ertekin B. Characteristics of the cases of bicycle and motorcycle accidents referred to the Emergency Department. Turk $J$ Emerg Med 2010; 10: 112-8.

18. Fabbri A, Marchesini G, Dente M, lervese T, Spada M, Vandelli A. A positive blood alcohol concentration is the main predictor of recurrent motor vehicle crash. Ann Emerg Med 2005; 46: 161-7. [CrossRef]

19. Akay N, Kurtoğlu Çelik G, Karakayalı O, Memeiş M, Tanrıverdi F, Vural S, et al. The effects of BACs on the severity of injury and on cost in the traumas caused by motor vehicle accidents. Ankara Med J 2014; 1: 5-10.

20. Akgul KG. After Traffic Accident Between 2000-2010 Epidemiological Investigation of patients presenting to the emergency department and Cost Analysis (Thesis). Ankara: Hacettepe University Medical School Emergency Medicine, 2011.

21. Runciman P, Currie CT, Nicol M, Green L, McKay V. Discharge of elderly people from an accident and emergency department: evaluation of health visitor follow-up. J Adv Nurs 1996; 24: 711-8. [CrossRef]

22. Dur A, Kocak S, Cander B, Sonmez E, Civelek C. Factors affecting mortality in patients with multitrauma which were treated in intensive care unit. Dicle Med J 2013; 40: 177-82.

23. Kara I, Altinsoy S, Gok U, Onur A, Saribapicci R. Mortality Analysis of trauma patients in General Intensive Care Unit of a state hospital. Journal of Turkish Society of Intensive Care 2015; 13: 68-74. [CrossRef] 